\title{
Representações sociais do trabalho para o menor aprendiz
}

\author{
Fábio Junior Manzioli', Patrícia Ortiz Monteiro²
}

\begin{abstract}
Resumo
Este estudo trouxe como desígnio identificar as representações sociais trabalho para adolescentes trabalhadores. Tocante ao referencial teórico-metodológico da pesquisa, utilizou-se a Teoria das Representações Sociais, além de uma interlocução a temas subjacentes a adolescência e trabalho. Tratou-se de um estudo realizado por meio de pesquisa exploratória com abordagem qualitativa. Foram entrevistados 20 (vinte) adolescentes trabalhadores participantes do Programa Aprendizagem, de uma instituição de ensino profissional, em um município do Vale do Paraíba Paulista. Foi utilizado como instrumento um roteiro semiestruturado com perguntas abertas, por meio do qual granjeou-se identificar as crenças, considerações, atitudes e valores dos sujeitos, atinentes ao objeto do estudo, o qual foi tratado com o uso do software Iramuteq. Os dados analisados de uma das classes de palavras denominada "Aprendiz" indicaram que os adolescentes representam a si próprios com conceitos complexos e multifacetados, mormente apresentando uma imagem pejorativa, ancorada na figura de Aprendiz como escravo.
\end{abstract}

Palavras-chave: Representações Sociais. Adolescência. Desenvolvimento Humano.

\begin{abstract}
This study has provided as a design identify the social representations work for adolescent workers. Regarding the theoretical-methodological reference of the research, the Theory of Social Representations was used, as well as an interlocution to themes underlying about adolescence and work. This study was accomplished through exploratory research with a qualitative approach. Twenty (20) adolescent workers were interviewed in the Learning Program of a professional education institution in a municipality located in the "Vale do Paraíba Paulista". A semi-structured script with open questions was used as instrument to identify the beliefs, considerations, attitudes and values related to the study object, which was treated using the "Iramuteq" software. The analyzed data of one of the word classes of words denominated "Apprentice" indicated that the adolescents represent themselves with complex and multifaceted concepts, mainly presenting a pejorative image, anchored in the figure of Apprentice as a slave.
\end{abstract}

Keywords: Social representations. Adolescence. Human development.

\footnotetext{
${ }^{1}$ Mestrando em Desenvolvimento Humano pela Universidade de Taubaté (UNITAU) - pedrofernandes845@gmail.com

${ }^{2}$ Doutora, professora na Universidade de Taubaté (UNITAU)
} 


\section{INTRODUÇÃO}

O comportamento do jovem ${ }^{1}$ em relação ao mundo do trabalho, constitui um tema de profundo interesse e preocupações para a sociedade. Essas preocupações são facilmente compreensíveis, dada a importância social e cultural do assunto. As discussões sobre este comportamento permeiam o cotidiano do núcleo familiar dos jovens, e estão presentes na pauta do Governo e de acadêmicos das Ciências Sociais ${ }^{2}$.

O trabalho infanto-juvenil é de tal forma notável no país que dados recém apresentados pelo relatório do Programa Internacional de Avaliação de Estudantes (PISA, 2015), apontam que o Brasil é um dos seis países com a maior taxa de jovens estudantes entre quinze e dezesseis anos no mercado de trabalho. Os dados demonstram que $43,7 \%$ dos jovens brasileiros, declaram exercer alguma atividade remunerada em seu dia a dia, seja antes ou depois de irem à escola (OCDE, 2015).

Com este cenário, urge compreender o trabalho, como um dos bastiões do desenvolvimento humano, e ainda, considerar sua capacidade de fomentar a socialização dos jovens para os papéis da vida adulta. Com efeito, a socialização do jovem com papeis da vida adulta, pode ser melhor compreendida sob a ótica das Representações Sociais (RS), tendo em conta a existência de um objeto (trabalho) e um sujeito (jovem), e de que este sujeito é um ator social influente afetado por diferentes elementos em seu cotidiano.

De acordo com Jodelet (2009, p.697), o estudo das Representações sociais:

[...] permite acessar os significados que os sujeitos, individuais ou coletivos, atribuem a um objeto localizado no seu meio social e material, e examinar como os significados são articulados à sua sensibilidade, seus interesses, seus desejos, suas emoções e ao funcionamento cognitivo.

É com especial atenção às conjecturas propostas por Jodelet (2009), que se aprofunda a busca da compreensão de quais os significados, emoções e representações os jovens expressam em relação ao universo do trabalho. Além disso, esta visão, leva ao entendimento de como os estudos das Representações Sociais são importantes indicadores das práticas sócias cotidianas dos indivíduos, incluindo-se, evidentemente, elementos concernentes ao trabalho.

Ademais, o trabalho é um elemento central da vida dos indivíduos, Giordano (2000, p. 50), afirma que [...] "o trabalho assume um lugar importante como atividade humana e como realidade social, devido à sua frequência e relevância na vida das pessoas", e ainda, Nascimento e Miranda (2007, p. 171) argumentam que:

[...] o trabalho tem sido um dos principais temas estudados nas ciências humanas e sociais moderna e contemporânea. Mais do que sobrevivência, é uma das mais expressivas manifestações do ser humano, diferente de ser uma simples atividade que nos permite ter uma renda, contribui para o nosso bem-estar mental e emocional, satisfaz o desejo de ser membro produtivo da sociedade, e nos agrega ou retira a possibilidade de realização pessoal; portanto, cria e desenvolve em nós, certa medida de autoestima, de acordo com a utilização das potencialidades e competências individuais. 
Estas afirmações apontam para a importância do trabalho na vida humana, e sua relevância nas ciências sociais, fato que arrazoa a escolha das representações sociais como fundo para pesquisas deste significativo fator da esfera social. Ainda outra característica dos estudos em Representação Social é digna de nota, segundo Cavedon (1999, p. 3)

[...] elas (representações sociais) possuem um caráter prescritivo, impondo-se sobre os indivíduos como uma espécie de "força irresistível", incorporando estruturas de pensamento pré-existentes ao próprio sujeito. As representações ditam, de certa forma, o que deve ser pensado a respeito de um dado objeto.

Logo, pode-se compreender que o arcabouço teórico das Representações Sociais são um valioso instrumento para as pesquisas sociais.

A pesquisa, ora proposta, tem como objetivo identificar e compreender as representações sociais do trabalho para adolescentes participantes do Programa Aprendizagem.

\section{O DESEMPREGO ENTRE JOVENS E ADOLESCENTES BRASILEIROS}

No atual debate sobre as condições sociais, o desemprego é visto como um dos grandes problemas contemporâneos, ele afeta de forma homogênea economias desenvolvidas e economias em desenvolvimento. Segundo especialistas, o desemprego está associado a três hodiernos fatores: a mundialização dos mercados, que se firma na reestruturação da produção, o desenvolvimento e a introdução maciça de novas tecnologias no meio produtivo que utiliza cada vez menos mão-de-obra, e por último, o fim de um período de crescimento econômico sustentado, o qual subsidiava um sistema de pleno emprego encontrado em grandes economias (KATO; PONCHIROLLI, 2002).

No Brasil, o cenário do desemprego é ainda mais complexo, além de encerrar os elementos acima apresentados, o país passa nos últimos anos por uma forte crise econômica e política que culminou em 2016 no impeachment de sua Presidente da República, estes elementos fatalmente afetaram a já fragilizada economia do país, aumentando substancialmente o desemprego. Segundo dados do IBGE (2017), o Brasil possui 13,8 milhões de desempregados, deste contingente de pessoas sem ocupação, que somam quase $14 \%$ da população brasileira, surge outro dado alarmante, 31,8\% dos desempregados brasileiros são jovens entre 18 e 22 anos de idade, ou seja, um total de aproximadamente 4,5 milhões de jovens sem trabalho (SILVEIRA; CAVALLINI, 2017).

Somando-se a isso, dados apresentados pela Organização das Nações Unidas (ONU) demonstram que os jovens brasileiros estão em segundo lugar no ranking de pessimismo no que tange a trabalho. Aliás, segundo Pochemann (2000) sete em cada dez brasileiros não acredita que terá um futuro com condições de viver e trabalhar melhor que seus pais.

Aqui, convém uma pergunta, afinal de contas, quais são as prioridades na vida de jovens e adolescentes? Em um devaneio, a resposta a esta pergunta, certamente seria: o direto de praticar a cidadania; acesso à educação de qualidade; prática de esporte que desenvolva os jovens e afaste-os de atividades delituosas; acesso a atividades de lazer, que permitam enriquecimento cultural e social para estes sujeitos. Todavia, de fato, trata-se de um sonho, um devaneio como dito, posto que a realidade brasileira é muito distante deste cenário, como visto, aliás, segundo Pochemann (2000), 70 \% dos jovens não tem grandes perspectivas de trabalho em seu futuro.

Estas esferas da vida social, segundo o Estatuto da Criança e do Adolescente, deveriam ser uma das 
principais atribuições do Estado, porém, o poder público não consegue desenvolver uma rede de atenção aos elementos anteriormente mencionados, ficando assim, um grande abismo entre o ideal e o real nas prioridades da vida dos jovens brasileiros.

Asseverando as conjecturas acima, dados recém-publicados pelo relatório 2017 do PiSA, atestam que no Brasil, lamentavelmente, a prioridade de muitos jovens tem sido o trabalho; os dados mostram que o Brasil é um dos seis países no mundo com maior taxa de jovens estudantes entre 15 e 16 anos no mercado de trabalho. Segundo Bermúdez (2017, p. 2):

[...] 43,7\% dos jovens brasileiros nessa faixa etária declararam exercer algum tipo de trabalho remunerado em suas rotinas, antes ou depois de ir à escola. Com esse número, o Brasil fica atrás apenas da Tunísia $(47,2 \%)$, da Costa Rica (45,3\%), da Romênia (45,3\%), da Tailândia (43,9\%) e do Peru (43,8\%).

Estes números, mesmo que bastante elevados, subestimam a dimensão do problema por vários motivos. Primeiramente, porque o PNAD (Pesquisa Nacional por Amostra de Domicílios), inclui na lista de ocupados, apenas os indivíduos que estão trabalhando na semana da pesquisa. Entretanto, segundo Mazzotti (2002), o trabalho infanto-juvenil é tipicamente intermitente, fazendo com que muitas crianças e adolescentes que trabalham, não sejam incluídos na pesquisa, porque não atendem a este critério.

Outro agravante, para estimativas razoáveis do número de jovens trabalhadores, encontra-se no fato de que a Emenda Constitucional no 20, de 15/12/1998, proíbe o trabalho para menores de 16 anos, exceção feita apenas no caso de Aprendizes, fato este, que leva muitas vezes, o trabalho destes meninos e meninas a serem omitidos por medo de represálias aos pais, que permitem estas atividades, mesmo sabendo que a lei não o permite. Outro fenômeno que merece realce, é a tendência de os pais considerarem como "ajuda" o trabalho de crianças e adolescentes exercidas em suas residências junto a seus familiares, o que, certamente contribui para a diminuir os índices apresentados.

Finalmente, pode-se afirmar que "o trabalho das crianças de menos de 10 anos, na grande maioria dos casos, é exercido na agricultura, em áreas rurais, onde a visibilidade é também precária." (MAZZOTTI, 2002, p. 88).

\section{MÉTODO}

Esta pesquisa é exploratória com abordagem qualitativa, trazendo como referencial teórico a Teoria das Representações Sociais.

Como instrumento da pesquisa, optou-se por um modelo de entrevista semiestruturada, que focaliza especificamente as RS do trabalho para o Menor Aprendiz.

Para cumprir com os propósitos desta investigação optou-se por aplicar a pesquisa junto a 20 (vinte) adolescentes trabalhadores, participantes do Programa Aprendizagem de uma instituição de ensino em uma cidade do Vale do Paraíba Paulista, jovens estes, contratados por empresas da região, que desenvolvem atividades laborais na concomitância dos estudos regulares e cursos profissionalizantes na instituição supramencionada.

As entrevistas foram analisadas pelo software IRAMUTEQ. A partir dos resultados obtidos, os conteúdos das entrevistas foram classificados e agrupados em temas majorantes, constituídos a partir da similitude dos discursos dos entrevistados, visto que, o software apresenta um encadeamento fundamentado nas singularidades nos discursos dos sujeitos. Para fins desse trabalho, apresenta-se os resultados de uma das 
classes de palavras analisadas denominada "Aprendiz".

Foi ainda, utilizada a técnica de triangulação, que cumpriu o seguinte protocolo: foram levantados os dados empíricos consignados às narrativas depreendidas pelo discurso dos entrevistados; num segundo momento, foi realizado uma visita as erudições dos autores que amparam as temáticas circunscritas ao objeto de pesquisa (trabalho e RS); e finalmente, o terceiro eixo de atuação que foi à análise conjuntural, ou melhor, como a trama dos fatos se desencadeou, e como este quadro, tem conexão com a realidade abstrata e objetiva relacionada ao objeto.

\section{RESULTADOS}

O software Iramuteq, ao processar o corpus textual, gerou um diagrama denominado de "dendograma" com 5 classes de palavras.

Figura I - Dendograma.

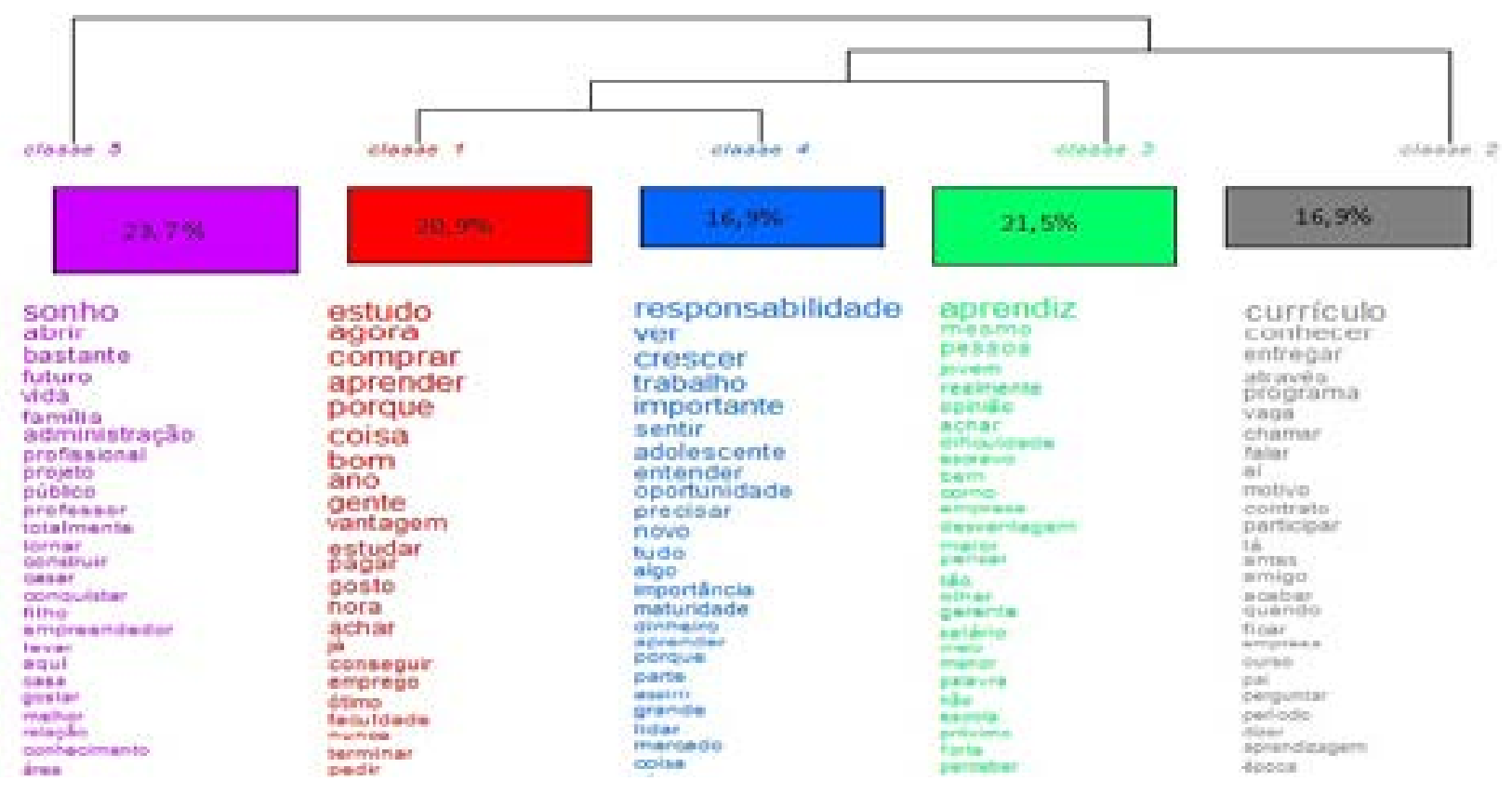

Fonte: Iramuteq, 2018.

Cada classe recebeu uma denominação específica em função das palavras com maior recorrência.

A classe "Aprendiz", classificada pelo Iramuteq como classe 3, foi tratada nesta pesquisa, dada sua notável relevância e centralidade representacional. Ademais, esta classe é a segunda em representatividade, ficando com $21,5 \%$ do total de incidência de palavras no corpus do texto analisado; as palavras aprendiz, trabalhar e jovem se repetem 169, 56 e 31 vezes respectivamente, sendo elas algumas das com maior incidência.

A tempo, nesta classe, apresentam-se amplas discussões sobre como os adolescentes materializam, objetivam o "ser" aprendiz. O que outrora era apenas um conceito, uma imagem, torna-se concreto, coadunando as ideias de Moscovici (1981, p.317), de que "elas adquirem a autoridade de um fato natural"; 
portanto, é quase ${ }^{3}$ possível afirmar que existem muitos elementos da fase denominada naturalização da objetivação.

Aqui, os adolescentes destacam as dificuldades vividas no dia-a-dia de seu trabalho, revelam os ganhos educacionais adquiridos, relatam elementos concernentes a baixo salário, e relevam ainda as desvantagens de fazer parte do Programa Aprendizagem.

Nota-se, que de modo geral, os sujeitos relacionam o "ser" aprendiz majoritariamente em aspectos desfavoráveis. Deste modo, são concatenadas 4 frentes representacionais de pertencimento à Classe Aprendiz.

Há à frente finanças, onde os aprendizes, em princípio, correlacionam seus rendimentos a noções negativas; com frequência os discursos mostram ideias de "baixo salário", "ganha-se pouco", "o salário não é muito" entre outras falas que conferem sentido negativo ao elemento salário. A seguir, destaca-se trechos das entrevistas que revelam estas visões, observa-se que a aprendiz 5 relata que "[...] e tem o aprendiz para auxiliar, eu acho que as pessoas pensam que o aprendiz é meio escravo, já vi muita gente falar: nossa você ganha muito pouco e pega ônibus e acorda cedo, e não sei o quê ..." (APRENDIZ 5).

Similarmente, outro jovem apresenta em seu discurso termos análogos para representar sua visão acerca dos rendimentos dos aprendizes

[...] meio complicado de responder, porque muitas pessoas acham que o jovem aprendiz trabalha como, [...] é uma palavra meio forte para falar, mas como escravos, pra alguns tem pessoas que acham assim, pelo fato de fazer algumas vezes um trabalho que não é pra fazer, e principalmente por ganhar pouco, mas boa parte das pessoas acham que o jovem aprendiz é pra quem não tem principalmente um emprego (APRENDIZ 11).

Os fragmentos mencionados, são os que apresentam maior ênfase negativa ao elemento salário, uma vez que manifestaram a ideia de "ser" aprendiz a escravidão, ideia essa que encontra seu germe na concepção de que trabalho escravo é igual a: trabalho não remunerado, abuso ou exploração; deste modo, associando a escravidão a elementos de falta de dinheiro.

Este aspecto, mostra-se como uma possível ancoragem, dado que, ancorar é submeter um objeto (neste caso - dinheiro), a um sistema de interpretação, apoiado num consenso social minimamente mensurável (relato dos aprendizes), enquadrando-o em uma rede de significados manifesto por normas e valores (ideia de escravidão), dito de outro modo, "ancoragem é um processo que integra algo não "familiar" e perturbador no nosso sistema de categorias comparando-o com um membro característico da categoria que consideramos ser apropriada" (MOSCOVICI, 2011, p.120).

Ainda outros entrevistados apresentam em seu discurso pontos de vista semelhantes como a aprendiz que diz que "A vantagem de ser aprendiz é porque o horário, ele é mais curto, então você tem uma carga horaria mais flexível, e a desvantagem é o salário que infelizmente é baixo" (APRENDIZ 3).

Quanto ao depoimento da aprendiz 3, apesar da ressalva a flexibilidade do horário, como ponto favorável, mais uma vez, explicitamente encontra-se menção a baixo salário como desvantagem de ser aprendiz.

[...] eu acho que a maior vantagem de ser aprendiz é que não há responsabilidades muito altas em cima de nós, não há pressão, não há 
uma exigência, mas a desvantagem, também, de ser aprendiz, eu acho que seria o salário é pequenininho, mas a maior desvantagem de ser aprendiz é você não ter, eu acho que, a maior desvantagem de ser aprendiz, na maior parte das vezes, é e que você não é valorizado, assim como se você não fizesse parte do grupo de trabalho, porque eles sabem que você é um aprendiz, entendeu? (APRENDIZ 9).

Analisando atentamente os relatos ora apresentados, é possível admitir que os entrevistados, implicitamente, avaliam que os empregadores buscam nos aprendizes uma mão de obra barata, e que não reconhecem seu devido "mérito". Assim, é possível dizer, que o Programa, tal como se apresenta atualmente, deve ser questionado e reavaliado pelo poder público no que concerne ao rendimento auferido aos aprendizes, uma vez que, mesmo quando as empresas concedem a empregados celetistas uma base salarial superior ao salário mínimo, aos aprendizes é facultado apenas a proporcionalidade das horas de trabalho correspondentes ao salário mínimo, que no ínterim desta pesquisa é $17 \%$ inferior ao salário do comércio (apenas como exemplo), fazendo com que o rendimento de muitos aprendizes não supere o valor de $\mathrm{R} \$ 550,00$ mês. Outros relatos aprofundam ainda mais este debate, como lê-se abaixo.

[...] eu aprendi muita coisa, e isso me vale muito, porque eu não conhecia nada, agora eu sei já um pouco, [...] e acho que a desvantagem é mais a questão do salário, acho que só depende da empresa, também que às vezes não pagam convênio, que a gente não tem mais, enfim, essas são algumas das desvantagens [...] (APRENDIZ 12).

Em todos os trechos apresentados, destacam-se elementos de finanças, confirmando-se, portanto, que na representação destes jovens, eles ganham pouco e que de certo modo, são "explorados" por seus empregadores. Tendo em vista, que ao serem questionados sobre quais seriam as possíveis vantagens ou desvantagens de ser menor aprendiz, quase todos, espontaneamente levantaram a baixa remuneração como critério negativo, sendo desta forma uma clara acepção de desvantagem.

Apenas no discurso de um sujeito aparece a alusão a uma remuneração justa, pois, para este, por trabalharem com uma carga horária menor é correto que eles ganhem proporcionalmente menos, assim, a jovem diz que "[...] acho que pelo trabalho e pelo curso que proporcionam eu acho que é um pouco o salário, mas eu acho que que é justo, porque pela jornada de trabalho e pelo curso também, eu acho que é um salário justo" (APRENDIZ 13).

Continuando as discussões tocantes a Classe Aprendiz, surgiu uma segunda frente, denominada desvantagem, nela, os aprendizes apontam abertamente opiniões circunstanciadas em conjunturas classificadas por eles como desfavoráveis. Circunstâncias essas da labuta comum a vida adulta; chefes de família, pais, mães, avós e outros que se desdobram no trabalho responsabilizando-se pelo sustento da família.

Neste ponto, distingue-se uma certa adultização, latente no processo do trabalho dos adolescentes, assim, a ideia seria razoável dizer que estes jovens experimentam um mergulho na vida adulta, uma vez que o trabalho

Trata-se de um processo de adultização precoce, em que a inserção no mercado de trabalho, quer seja formal, ou 'informal', é precária em termos de condições e níveis de remuneração. Esse processo de adultização dos jovens muitas vezes faz com que ele perca todo o seu tempo infanto-juvenil, não tendo direito de viver coisas que são peculiares à sua idade (ARAúJO, 2008, p. 99). 
Em vista disso, é relevante apresentar outro ponto de vista de Araújo (2008, p. 99), que em sua pesquisa declara que, por vezes a inserção do jovem no mercado de trabalho "[...] não se dá por escolha, mas em decorrência de um modelo de sociedade que vem sendo construída ao longo da história do Brasil", ou ainda outra concepção de que para o adolescente, "[...] o ingresso no mundo do trabalho constitui-se, tradicionalmente, em um dos principais marcos de passagem da condição juvenil para a vida adulta" (SILVA; NETO, 2012, p.3). Outros fragmentos corroboram essas ideias, como pode ser visto nos arbítrios exibidos nos próximos fragmentos das entrevistas.

[...] as dificuldades aparecem mais no momento que as pessoas acabam querendo aproveitar de você por você ser aprendiz, eles acabam jogando tudo que os outros não querem em cima de você, eu acho que a empresa muitas vezes pensa que aprendiz é só uma cota, precisa estar ali, porque se não tiver, talvez seja notificada, alguma coisa assim, então só está ali porque precisa ter [...] (APRENDIZ 3).

O fragmento acima, mostra uma profunda crítica do sujeito ao que ele vê como modelo "cultural" da empresa tocante aos aprendizes. Está implícito na fala "aproveitar de você", "aprendiz é só uma cota" que este sujeito interpreta (representa) que a empresa onde trabalha, não se preocupa com a qualidade das relações (profissionais/pessoais) com os aprendizes, tornando-os, por assim dizer, "subempregados", ou como frisa este jovem, o aprendiz "só está ali porque precisa ter", isto é, fazendo-se cumprir o que determina a lei quanto a cota de aprendizes por empresa ${ }^{4}$. Outro aspecto impactante neste depoimento, é relativo ao trabalho em si, ou seja, as atividades que devem ser feitas pelos aprendizes: "eles acabam jogando tudo que os outros não querem em cima de você", este fragmento, sugere que atividades vistas pelos funcionários da empresa (não aprendizes), como "chatas", "enfadonhas", ou meramente procedimentais são atribuídas aos aprendizes, posto que, eles não estão ali por "mérito", ou por serem "desejados", mas sim, pelo fato da empresa ser obrigada por força de lei a tê-los em seu quadro de funcionários. Na sequência, outras contribuições que respaldam esta visão.

[...] a maior desvantagem de ser aprendiz, na maior parte das vezes, você não é valorizado, assim como se você não fizesse parte do grupo de trabalho, porque eles sabem que você é um aprendiz entendeu? Eles não podem lançar certas coisas no seu nome, e às vezes o aprendiz quer evoluir, quer se sentir como parte da equipe, e ele não pode porque ele é aprendiz [...] (APRENDIZ 2).

[...] as pessoas não suportam os aprendizes, tô falando sério! Porque você passa do lado, as pessoas já te olham feio, não te falam bom dia, abaixam a cabeça como se a gente fosse um monstro, não é todo mundo, mas algumas pessoas são assim, acho que pelo cargo, as vezes elas acham que a gente não é capaz, não sei? [...] eu acho que eles desmerecem a gente (APRENDIZ10).

Ainda outras declarações seguem nesta mesma linha, todavia, estas qualificam a compreensão de que os jovens simbolizam que as empresas não os "incluem", não os tratam como "iguais" junto aos demais colaboradores, ou na fala dos próprios aprendizes: "ele não pode porque é aprendiz", "eles acham que a gente não é capaz", "desmerecem a gente". Fica, portanto, evidenciado, que estes sujeitos não sendo valorizados, nutrem o desejo de sê-lo, aspiram ser "vistos" como parte da equipe, o sentimento de pertença, consequentemente está ausente na representação destes sujeitos. 
Ainda outros desdobramentos são passíveis de análise a partir da frente desvantagem, a variável tempo e adaptação são exemplos. Aqui os relatos mais comuns versam sobre o como a rotina dos adolescentes foi modificada a partir do início das atividades profissionais e consequentemente a difícil adaptação a nova rotina. A seguir, lê-se dois depoimentos neste sentido.

[...] uma dificuldade, a adaptação pelo menos no meu caso foi a adaptação, e para os outros adolescentes (talvez), seja a mesma coisa pois eles saem da escola geralmente, sai da escola e vai [...] à tarde fazer um curso e tudo mais, então adaptar com o serviço é um pouco difícil, é um impasse, mas com o tempo acaba se adaptando (APRENDIZ 4).

[...] desvantagem é que tem que estudar e trabalhar ao mesmo tempo, e o salário não é adequado pra tudo isso que a gente faz. (APRENDIZ 16).

Um componente que pode ajudar a esclarecer este ponto, encontra-se na constatação de que aproximadamente 141 (69,80\%) deles estudam na concomitância das atividades profissionais. Portanto, é de se esperar que os adolescentes sintam o impacto do novo ritmo de vida.

Continuando as discussões relativas a Classe Aprendiz, restam ainda duas frentes a serem analisadas, as frentes empresa e aprendizado. Assim, compreendendo a relevância destas frentes na presente pesquisa, e na tentativa de garantir maior respaldo em sua análise, elas foram minuciosamente tratadas.

\subsection{CLASSE “APRENDIZ”: ANÁLISE DA ZONA MUDA}

Ao pensar as questões norteadoras que seriam utilizadas nas entrevistas, buscou-se, aventar aspectos do objeto representacional a níveis mais concretos e habituais, a elementos mais abstratos ao contexto dos fenômenos. Dessa maneira, foram utilizadas duas técnicas distintas na elaboração das questões. A primeira delas, direta, por meio de perguntas com linguagem natural próxima ao contexto onde se desdobram os eventos, visando a espontaneidade das respostas dos sujeitos.

A segunda técnica, fundamentada no entendimento de Silva e Ferreira (2012), de que certos elementos da RS podem ser compreendidos como "contranormativos", não aparecendo espontaneamente nos discursos, tendo que "[...] cognições ou crenças que não são expressas pelo sujeito em condições normais de produção, pois podem entrar em conflito com valores morais ou normas do grupo" (SILVA; FERREIRA, 2012, p. 610).

Nesta perspectiva, a fim de investigar a zona muda das representações, foi aplicada a técnica de substituição e descontextualização normativas. Esta técnica, baseia-se na ideia de que um sujeito poderá exprimir representações "proibidas ao seu grupo" atribuindo-as a outros, isto é, falando por outros (SILVA; FERREIRA, 2012, p.610).

Com isso, foram apresentadas aos entrevistados duas questões com a técnica de substituição, são elas: o que você acha que a empresa pensa sobre os aprendizes? e, o que você acha que as pessoas pensam sobre os aprendizes?

Logo, vê-se, que estas perguntas estão eminentemente ligadas a Classe Aprendiz. Contudo, uma vez empregadas as perguntas nas entrevistas, observou-se que delas, surgiram representações dicotômicas ao objeto (aprendiz); as respostas a questão 1 foram predominantemente valorativas, já as respostas a pergunta 2 obtiveram relatos majoritariamente desfavoráveis, deste modo, buscando garantir isonomia a esta pesquisa, ambas visões serão apresentadas. 


\subsubsection{ANÁLISE DA ZONA MUDA - O QUE VOCÊ ACHA QUE A EMPRESA PENSA SOBRE OS APRENDIZES?}

Um importante aspecto retratado na fala da Aprendiz 2, encontra-se no evidente caráter "figurativo" da fala; ao apresentar o que ela acredita ser o pensamento da empresa tocante aos aprendizes.

[...] assim, eu vejo que as empresas pensam... as empresas vêm os jovens aprendizes como uma boa oportunidade para eles também, que lá eles podem... é como se fosse uma planta que eles vão aguando até virar uma grande árvore, então, eu acho que a empresa ao meu ver, eles pensam isso; e eles treinam capacitam para isso, para ter um grande fruto depois [...] (APRENDIZ 2).

É possível então, atribuir ao discurso desta jovem, o que Moscovici (1981, p.199) sugere ser uma objetivação; segundo o autor objetivar é "[...] descobrir o aspecto icônico de uma ideia ou ser impreciso, é colocar/emparelhar o conceito a imagem, é dar-lhe substância e associar essa ideia ou ser a um significado concreto e compreensível". Aliás, a objetivação presente neste fragmento, pode ser relacionada a fase da objetivação denominada por Jodelet (1984) como esquematização estruturante ou esquema figurativo, uma vez que "[...] num esquema figurativo as noções básicas, que constituem a representação, organizam-se constituindo um padrão de relações estruturadas, isto é, simplificam e unificam imagens que eram inicialmente desconectadas" (SILVA, 2011, p. 118).

Continuando, o esquema figurativo apresentado pela aprendiz 2, que alude a elementos de "plantio", "cuidado" para uma posterior "colheita de fruto", ou ipsis litteris "como se fosse uma planta que eles vão aguando até virar uma grande árvore, [...] para ter um grande fruto depois", estes elementos, demonstram aspectos de valor representacional imbricados a um viés formativo, de aprendizado e capacitação, ou seja, segunda ela, a empresa busca a qualificação dos aprendizes para, colher os frutos deste "investimento".

Confirmando este entendimento, a mesma jovem, diz ainda que "[...] eu acho a empresa vê os aprendizes como os menorzinhos, as crianças de lá; é como o prézinho de uma escola, eu vejo assim, claro, eles também visam o futuro [...]" (APRENDIZ 2).

Uma vez mais, o discurso aponta para elementos figurativos e futuros, vinculados a um investimento na educação e profissionalização dos adolescentes para o porvir da empresa, tratando-os como crianças a serem educadas.

A seguir, mais um entrevistado traz em sua resposta elementos figurativos, ele diz "[...] acho que a e empresa enxerga o aprendiz como algo novo, algo a ser explorado, uma jóia que precisa ser lapidada para o mercado" (APRENDIZ 18). Aqui, novamente, vê-se uma objetivação circunscrita no uso de uma figura (objeto jóia), desta vez, alusiva à ideia de "valor" e "preciosidade" do aprendiz, que ainda não está pronto, que precisa ser "lapidado", "capacitado" para o mercado de trabalho.

Mais um sujeito demonstrou princípios relativos a futuro em sua resposta, isto é, imaginando que a empresa tende a absorver em seu quadro de colaboradores os aprendizes que por sua vez, dedicarem-se e "mostrarem serviço". Assim, quando indagado com a questão 1 ela respondeu que em sua visão a empresa pensa "[...] que (o aprendiz) é o futuro da empresa, e a gente vai poder ajudar as outras pessoas... se a gente mostrar serviço, e se a gente se dedicar, a gente pode até ser efetivado" (APRENDIZ 16).

Neste depoimento assim como nos anteriores, fica também evidente que as empresas, segundo a visão destes sujeitos, usam o Programa Aprendizagem como "laboratório", ou como no jargão da área como 
um "trampolim" para futuras contratações, e este fator está em consonância com a Lei 10.097/2000, Lei da Aprendizagem, que em seu escopo busca por meio do Programa uma primeira oportunidade de inserção de jovens e adolescentes no mercado de trabalho.

[...] Então, salvo algumas pessoas, a empresa pensa do aprendiz... é, acho que, como o entusiasmo que faltava, acho que sangue novo, a intensão de aprender... acho que a empresa pensa que o aprendiz revigora a equipe, traz inovação, criatividade, acho que é nesse sentido" (APRENDIZ 8).

Um olhar muito particular aparece no discurso desta jovem. Ao debruçar o olhar sobre a adolescência ver-se-á que, de fato, a concepção de juventude "entusiástica", "criativa" encontra amparo nos autores Stengel e Tozo (2010, p.74), "[...] associação entre adolescência e inovação/renovação é uma ideia que se faz presente em nossa sociedade". Neste caso, a aprendiz, atesta que na empresa onde trabalha, o espírito atribuído aos adolescentes por Stengel e Tozo (2010), Ariès (1978) e Justo (2005) são também compartilhados pelos gestores da empresa.

Dando continuidade, surge mais um depoimento fortemente vinculado a aspectos relacionados a futuro. A seguir constata-se este depoimento.

[...] na minha opinião, as empresas enxergam os aprendizes como: o futuro da empresa! Porque a maioria que está lá dentro da empresa já vai se aposentar, eles são pessoas mais experientes que não tem muito contato com a tecnologia, então o aprendiz, ele pode levar uma coisa nova para empresa, que pode ser uma solução para um problema que ele tem lá dentro, e eles não sabem como resolver (APRENDIZ 19).

Num primeiro olhar ao fragmento acima, vê-se que esta jovem associa a visão da empresa a uma possível "renovação", uma vez que, possivelmente, alguns profissionais da empresa estão na eminencia da aposentadoria. E ainda, de acordo com seu relato, a empresa vincula os aprendizes a pessoas com potencial para resolução de problemas, posto que, implicitamente ela faculta aos aprendizes elementos novos (conhecimentos tecnológicos), que podem solucionar os problemas internos da empresa.

Neste depoimento, similarmente aos anteriores, observa-se fundamentos tocantes ao futuro profissional do aprendiz, assim, o jovem relata que "[...] A empresa? Ela pensa que a gente está lá para auxiliar, principalmente em várias áreas, e eu vejo muito que eles querem que eu cresça profissionalmente, então eles me permitem conhecer coisas diferentes, fazer coisas diferentes" (APRENDIZ 7).

Em síntese, este jovem percebe que a empresa quer que ele se desenvolva como profissional, permitindo inclusive que ele conheça as tarefas características de cada setor, ou como eu sua fala "conhecer coisas diferentes".

De um modo geral, os resultados apurados, apontam que quando indagados sobre o que eles acham que as empresas pensam sobre os aprendizes, houve preponderância de respostas positivas atrelando a visão da empresa a concepções valorativas sobre os adolescentes. Com isso, pode-se dizer que há, elementos de objetivação nestas falas, considerando que Jodelet (1984, p. 116), afirma que o paradigma da objetivação "[...] aparece como generalizável a toda a representação e comporta aspectos importantes do ponto de vista da lógica e funcionamento do pensamento social", ainda, segunda a autora, outras funções são percebidas na objetivação, a saber: "[...] revelar a tendência do pensamento social para uma construção estilizada, imagética e significante; mascarar ou acentuar elementos constitutivos do objeto de representação para servir as necessidades, os valores e interesses do grupo [...]" (JODELET, 1984, p. 116). Assim sendo, é crível que os aprendizes objetivem os elementos "aprendizado", "inovação/criatividade", "futuro" e "efetivação" tocantes a pergunta. 


\subsubsection{ANÁLISE DA ZONA MUDA - O QUE VOCÊ ACHA QUE AS PESSOAS PENSAM SOBRE OS APRENDIZES?}

Como dito anteriormente, surge uma aparente dicotomia no resultado da análise da zona muda das representações, especialmente quando comparadas as respostas da primeira com as respostas da segunda questão. Na primeira houve preponderância positiva, na segunda contrariamente, houve predomínio negativo nas respostas.

[...] acho que tem muitas pessoas que vem como um subtrabalho, como se não fosse um trabalho de verdade, como se fosse algo que você faz só pra passar o tempo, eu já ouvi muito eles falarem, quando você vai arrumar um trabalho de verdade? Já ouvi eles falarem isso, então isso me deixou um pouco magoado, porque é um trabalho! Você está trabalhando e aprendendo! [...] acho que todos os trabalhos deveriam ser uma aprendizagem (APRENDIZ 1)

O depoimento deste sujeito, externa uma visão de que as pessoas dão ao aprendiz uma representação de "subemprego", de uma atividade laboral menos importante, vinculada a um entendimento de que o adolescente está ali apenas para "passar o tempo", e que em breve ele deve ir em busca de um trabalho de verdade. A seguir, outro depoimento.

[...] então, infelizmente acho que o senso comum em relação a aprendizagem é um pouco negativa, no sentido de a carga ser menor, e não estar apto a fazer muitas coisas, então algumas pessoas julgam [o aprendiz] como incapazes como não trabalhadores de verdade (APRENDIZ 8).

A jovem amplia o horizonte de sua resposta a um suposto "senso comum", ou seja, a um modo de pensar da maioria das pessoas, tocante à figura do aprendiz, nesta perspectiva, implicitamente, a jovem alude a uma RS de que o aprendiz é inapto, e por consequência incapaz de realizar certas atividades profissionais.

Este fragmento, guarda muita semelhança ao depoimento anterior, tendo em vista que ambos referem-se a uma possível objetivação de que o aprendiz não é um "trabalhador de verdade", sendo tão somente uma atividade laboral de "passa tempo".

Ainda outros fragmentos associam-se a estes pontos de vista, a seguir, verifica-se mais alguns.

[...] olha, eu acho que é meio que... quando pensam em jovem aprendiz, elesjá pensam que a pessoa émeio imatura né, porque, normalmente émenor que pode trabalhar como jovem aprendiz, eu acho que eles meio que olham com olhar de imaturidade para a pessoa (aprendiz) (APRENDIZ 13).

Aqui um novo elemento surge nos discursos, evidenciando a existência de uma visão de imaturidade ao aprendiz, eventualmente, apenas por ser menor. Essa visão de imaturidade pode estar associada a visão de Folle e Geib (2004) que afirmam que "o alcance da maturidade decorrente da aceitação de novos papéis sociais confere-lhe o status adulto desejado", ou seja, segundo este relato, há uma visão generalizada de que falta aos aprendizes este status de maturidade associada a figura de um adulto.

Dando prosseguimento a análise dos discursos, outro aprendiz relata que:

[...] (têm) muitas pessoas que pensam negativo sobre o jovem aprendiz, acham que estão ali para perder tempo, que não tem essa questão de tá fazendo o curso, de estar trabalhando poucas horas, tem 
que ter um serviço mais fixo, tem que ganhar um pouco a mais, tem que ralar na vida, sendo que não é bem assim [...] (APRENDIZ 17).

O sujeito 17, argumenta que, via de regra, as pessoas têm uma visão negativa sobre os aprendizes, arraigada em preconceitos de que trabalham poucas horas, portanto, não é, por assim dizer, um trabalho "fixo" (efetivo), e ainda, o fato de estarem fazendo um curso profissionalizante na concomitância do trabalho, não alivia esta visão limitada sobre o aprendiz. O fato é que, o aprendiz é um trabalhador em formação, um jovem que está "aprendendo" um fazer profissional.

Ainda chama atenção neste fragmento o elemento "ralar na vida", um subproduto da cultura brasileira que firma-se no pressuposto de que somente pelo emprego de muito esforço, de muita dedicação e empenho é que se pode "vencer" na vida, logo, nesta fala, fica evidenciado que para o sujeito as pessoas pensam que os aprendizes não são meritórios da concepção de empenhados, dedicados ou vitoriosos.

Um último e oportuno fragmento, ainda é cabível para este secionamento, nele o aprendiz relata que “[...] acho que o pessoal pensa que, nossa! Você é aprendiz!? Você ganha pouco, você está trabalhando como escravo... que não vale a pena você ralar tanto para ganhar tão pouco [...]" (APRENDIZ 9).

Na fala deste sujeito, surge mais uma vez uma inferência a escravidão, elemento também presentes no discurso de outros sujeitos, mostrando uma forte vinculação de exploração dos jovens por meio do trabalho mal remunerado.

Observa-se a partir dos discursos apresentados que repetidamente os sujeitos entrevistados atribuem a "terceiros" a representação de ser aprendiz a "perda de tempo", "não é um trabalho de verdade", "imaturidade" e ainda outras concepções negativas que subjazem da figura do aprendiz.

Com efeito, o esquema apresenta um padrão estruturante das relações que organizam as RS ; a esfera subjetiva e a esfera objetiva, por meio da qual o processo de recalcamento simplifica e iguala concepções ou imagens que a princípio eram desconexas. De modo geral, o processo de recalcamento é apresentado por Tomaselli (2007), como sendo uma operação pela qual o indivíduo busca repelir ou manter no inconsciente representações (pensamentos, imagens, recordações) ligadas a um objeto representacional.

\subsubsection{ANÁLISE DA ZONA MUDA: DESFECHOS}

Como salientado anteriormente, urge a compreensão de que "as representações sociais devem ser percebidas como produções subjetivas que têm fundamento em uma realidade social, na qual também intervêm processos de subjetivação que a configuram" (GONZÁLES REY, 2003, p.433), assim, este entendimento, é um importante passo na observação e análise dos fenômenos associados a RS. Ainda, a partir desse ponto de vista, é possível dizer que:

[...] as representações sociais expressam realidades sociais que não se esgotam em sua expressão discursiva e nem na linguagem porque são parte de um tecido social constituído e organizado historicamente, que se reproduz não só nos espaços conversacionais, mas também na constituição subjetiva de seus protagonistas (MÍTJÁNS MARTíNEZ; GONZÁLEZ REY, 2006, p.83).

Com efeito, há um padrão estruturante das relações que organizam as RS; a esfera subjetiva e a esfera objetiva, por meio da qual o processo de recalcamento simplifica e iguala concepções ou imagens que a 
princípio eram desconexas. De modo geral, o processo de recalcamento é apresentado por Tomaselli (2007), como sendo uma operação pela qual o indivíduo busca repelir ou manter no inconsciente representações (pensamentos, imagens, recordações) ligadas a um objeto representacional.

Assim sendo, segue-se uma análise das RS amealhadas por meio da técnica de substituição. Conforme anteriormente registrado, houveram nas respostas às questões norteadoras 1 e 2 uma clara dicotomia. Esta dicotomia, pode encontrar seu germe no distanciamento dos sujeitos frente ao objeto (aprendiz). Sendo mais claro, quando os respondentes atribuíram fala a um terceiro, verificou-se que quanto mais próximos do círculo comum ao objeto está este terceiro, existe uma certa familiaridade ao objeto, deste modo, surgem nas respostas elementos valorativos e afirmativos quanto ao objeto analisado. Diametralmente oposta à está erudição, quando estes terceiros estão circunscritos a um certo distanciamento ao meio comum ao objeto, menor será a familiaridade, e uma visão mais crítica e negativa emerge nos discursos dos respondentes.

Ou seja, tendo em conta que as empresas na figura dos gestores e outros atores que participam da administração da empresa, participam ativamente da formação, acompanhamento e avaliação do trabalho dos aprendizes, eles têm um lugar de fala muito próxima aos aprendizes, fortalecendo, na visão dos respondentes, uma representação (muda) afirmativa quanto ao objeto. E na esteira oposta, as pessoas que de modo geral guardam um distanciamento dos eventos que circunscrevem a rotina dos aprendizes, foram representadas no discurso dos sujeitos de uma forma negativa e crítica ao objeto. No fragmento adiante apresentado, a jovem sintetiza estas deduções ao afirmar que "[...] a pessoa que vive perto de um aprendiz vê a importância sim do trabalho de um aprendiz, mas pessoas de fora, muitas vezes, acham que o aprendiz é um quebra galho, é um preguiçoso porque trabalha menos" (APRENDIZ 3).

Deste modo, a análise da zona muda das representações sociais sobre o Aprendiz, revelou que os entrevistados, expressam um posicionamento generalista, objetivando invariavelmente, que as empresas representam aspectos favoráveis ao aprendiz e que as pessoas sistematicamente representam os aprendizes pejorativamente.

\section{CONSIDERAÇÕES FINAIS}

As dicotomias apresentadas pelos adolescentes, tocantes à suas representações do objeto "aprendiz", caracterizam-se por múltiplas subjetividades sociais, que se distinguem por seu liame histórico cultural, num contexto que contribui para a construção desta dualidade de formas e pontos de vistas acerca do objeto.

Neste sentido, não causa estranheza que os entrevistados indicaram que os adolescentes representam a si próprios com conceitos complexos e multifacetados, mormente apresentando uma imagem pejorativa, ancorada na figura de Aprendiz como escravo de alguém que não recebe o devido reconhecimento financeiro das organizações que trabalham.

\section{REFERÊNCIAS}

ARAÚJO, Maria Dalvaneide de Oliveira. O PROGRAMA APRENDIZAGEM: UM ESTUDO DA FORMAÇÃO DO JOVEM APRENDIZ NO SENAC/PE. 2018. 168 f. Dissertação (Mestrado) - Curso de Mestrado em Educação, Universidade Federal de Pernambuco, Recife, 2008. Disponível em: <https://repositorio.ufpe.br/bitstream/123456789/4366/1/arquivo3645_1.pdf>. Acesso em: 02 maio 2018.

BERMÚDEZ, Ana Carla. No Brasil, 44\% dos estudantes de 15 e 16 anos trabalham, mostra ranking. 2017. Dados da OCDE. Disponível em: <https://educacao.uol.com.br/noticias/2017/04/19/no-brasil-44-dos-estudantes-de-15-e-16-a- 
nos-trabalham-mostra-ranking.htm>. Acesso em: 25 jul. 2017.

BRASIL. 2016 IBGE - Instituto Brasileiro de Geografia e Estatística. Ministério das Cidades. IBGE: Dados Gerais dos Municípios. 2014. Disponível em: <http://cidades.ibge.gov.br/painel/painel.php?lang=\&codmun=355030\&search=sao-paulo|sao-paulo|infograficos:-dados-gerais-do-municipio>. Acesso em: 01 maio 2017.

BRASIL. OECD. Programme for International Student Assessment (PISA). 2015. Disponível em: <https://www.oecd. org/pisa/PISA-2015-Brazil-PRT.pdf>. Acesso em: 30 abr. 2017.

CAVEDON, Neusa Rolita. As representações sociais dos universitários sobre o trabalho. In: Encontro CHAMON, Edna Maria Querido de Oliveira. Representações sociais da formação docente em estudantes e professores da Educação Básica. Psicologia Escolar e Educacional, [s.I.], v. 18, n. 2, p.303-312, ago. 2014. FapUNIFESP (SciELO). http://dx.doi. org/10.1590/2175-3539/2014/0182751.

FOLLE, Emanuele; GEIB, Lorena Teresinha Consalter. Representações sociais das primíparas adolescentes sobre o cuidado materno ao recém-nascido. Revista Latino-americana de Enfermagem, [s.l.], v. 12, n. 2, p.183-190, abr. 2004. FapUNIFESP (SciELO). http://dx.doi.org/10.1590/s0104-11692004000200006

GIORDANO, Blanche Warzée. (D)eficiência e trabalho: analisando suas representações. São Paulo, Annablume:FAPESP, 2000. 168p.

GONZÁLEZ REY, Fernando Luís. (2003). Sujeito e subjetividade: Uma aproximação Histórico-cultural. São Paulo, SP: Pioneira Thompson.

GONZÁLEZ REY, Fernando Luiz. (2003). Sujeito e subjetividade: Uma aproximação histórico-cultural. São Paulo, SP: Pioneira Thompson.

JODELET, Denise. O movimento de retorno ao sujeito e a abordagem das representações sociais. Sociedade e Estado, [s.I.], v. 24, n. 3, p.679-712, dez. 2009. FapUNIFESP (SciELO). http://dx.doi.org/10.1590/s0102-69922009000300004.

KATO, Jerry Miyoshi; PONCHIROLLI, Osmar. O desemprego no Brasil e os seus desafios éticos. Revista da Fae, Curitiba, v. 3, n. 5, p.87-97, set. 2002. Semestral.

MAZZOTTI, Alda Judith Alves. A abordagem estrutural das representações sociais. Psicologia da Educação, São Paulo, v. 15, n. 14, p.17-37, jul. 2002. Semestral. Disponível em: <https://revistas.pucsp.br/index.php/psicoeduca/article/ view/31913>. Acesso em: 05 maio 2018.

MOSCOVICI, Serge. (1976). La psychanalyse, son image e son public. Paris: PUF

MOSCOVICI, Serge. A representação social da psicanálise. Tradução de Cabral. Rio de Janeiro: Zahar, 1981.

NASCIMENTO, Eliane de S.; MIRANDA, Therezinha Guimarães. O trabalho e a profissionalização das pessoas com defici- 
ência. Revista da FACED. Salvador, v. 12, n. 12, 2007. p. 169 - 184. Disponível em http://www.portalseer.ufba.br/index. $\mathrm{php} / \mathrm{rfaced} / \mathrm{article} / \mathrm{view} / 2761 / 1949$. Acesso em 17 de fevereiro de 2010.

POCHMANN, Marcio; Batalha pelo Primeiro Emprego. São Paulo: Publisher Brasil, 2000.

SILVA, Aurora Maria Ribeiro da. REPRESENTAÇÕES SOCIAIS DA VELHICE. 2011. 392 f. Tese (Doutorado) - Curso de Doutorado em Psicologia, Faculdade de Psicologia e Ciências da Educação da Universidade do Porto, Universidade do Porto, Porto, 2011.

SILVA, Marcos Antonio Batista da; NETO, João Clemente de Souza. Inserção no mundo do trabalho: percepção do adolescente do ensino médio. 2012.

SILVA, Rafael Celestino da; FERREIRA, Márcia de Assunção. CONSTRUINDO O ROTEIRO DE ENTREVISTA NA PESQUISA EM REPRESENTAÇÕES SOCIAIS: COMO, POR QUE, PARA QUE. Esc Anna Nery, Rio, v. 3, n. 16, p.607-611, jul. 2012. Trimestral.

SILVEIRA, Daniel; CAVALLINI, Marta. Desemprego fica em 13,3\% em maio e atinge 13,8 milhões. 2017. Disponível em: <http://g1.globo.com/economia/noticia/desemprego-fica-em-133-no-trimestre-encerrado-em-maio.ghtml>. Acesso em: 25 jul. 2017.

STENGEL, Márcia; TOZO, Stella Maria Poletti Simionato. Projetos Afetivo-Sexuais por Adolescentes e seus Pais. Pesquisas e Práticas Psicossociais, São João Del-rei, v. 1, n. 5, p.72-82, jul. 2010. Semestral. Disponível em: <https://www.ufsj. edu.br/portal2-repositorio/File/revistalapip/volume5_n1/stengel_e_tozo.pdf>. Acesso em: 25 abr. 2018.

TOMASELLI, Tatiana Renaux. A psicologia do mercado acionário: representações sociais de investidores da BOVESPA sobre as oscilações dos preços. Estudos de psicologia, v. 12, n. 3, p. 275-283, 2007.

VELOZ, Maria Cristina Triguero; NASCIMENTO-SCHULZE, Clélia Maria; CAMARGO, Brigido Vizeu. Representações sociais do envelhecimento. Psicologia: Reflexão e Crítica, [s.I.], v. 12, n. 2, p.479-501, 1999. FapUNIFESP (SciELO). http://dx. doi.org/10.1590/s0102-79721999000200015. 